\title{
49th Annual Meeting of the Society for Research into Hydrocephalus and Spina Bifida Stephen Brown*
}

\author{
Address: Honorary Publication Secretary, Society for Research into Hydrocephalus and Spina Bifida \\ Email: Stephen Brown* - sbrown.osborne@btopenworld.com \\ * Corresponding author
}

from 49th Annual Meeting of the Society for Research into Hydrocephalus and Spina Bifida

Barcelona, Spain, 29 June -2 July 2005

Published: 30 December 2005

Cerebrospinal Fluid Research 2005, 2(Suppl I):SI doi: 10.I I86/I743-8454-2-SI-SI

The $49^{\text {th }}$ Annual Meeting of the Society for Research into Hydrocephalus and Spina Bifida was held in Barcelona, Spain, from $29^{\text {th }}$ June to $2^{\text {nd }}$ July 2005 . We are especially grateful to Amparo Cuxart and Esther Pages who, together with their team, made us all very welcome.

The city of Barcelona has much to offer, from the medieval elegance of the Gothic Quarter, to the rather more idiosyncratic architecture of Antonio Gaudi. Nor should it be forgotten that Picasso who spent much of his working life in Paris, was a Spaniard, who lived for many years in Barcelona.

Barcelona is the main Catellan city, and we were treated to a feast of Catellan history, culture and language, as well as the more modern icons who play for Barcelona FC.

The scientific sessions, held in the comfortable venue of the Hospital Universitari Vall d'Hebron, produced a great variety of topics, from cutting edge scientific research on hydrocephalus to very valuable work on the functional problems of children with spina bifida. Undoubtedly the highlight of the scientific programme was the Casey Holter Lecture given by John Mazur. John treated us to a fascinating insight into the orthopaedic management of patients with spina bifida, and brought to the task a working lifetime of experience.

Finally a warm welcome was extended by Hugh Richards, to the $50^{\text {th }}$ Annual Meeting which will be held in Cambridge, England from 30th August to 2nd September 2006. 